\title{
Augusto y el Noroeste de Hispania: la acción del emperador y las comunidades indígenas ${ }^{1}$
}

\author{
$\mathrm{M}^{\mathrm{a}}$ Dolores Dopico CAÍnZos \\ Universidad de Santiago de Compostela \\ mdolores.dopico@usc.es \\ Juan SANTOS YANGUAS \\ Universidad del País Vasco-EHU \\ juan.santos@ehu.es
}

\section{RESUMEN}

En este trabajo queremos analizar los cambios administrativos e institucionales que el emperador Augusto introduce en las comunidades indígenas del Noroeste inmediatamente después de la conquista.

Palabras clave: Augusto. Noroeste hispano. Comunidades indígenas. Administración del Noroeste.

\section{August and Northwestern Hispania: The Emperor's Role in the Indigenous Communities}

\begin{abstract}
In this paper we want to analyze the administrative and institutional changes that the emperor Augustus introduced in the indigenous communities of the northwest immediately after the conquest.
\end{abstract}

Key Words: Emperor Augustus. Northwestern Hispania. Indigenous communities. Administration of northwestern Hispania.

\footnotetext{
1 Este trabajo ha sido realizado en el marco del Proyecto de Investigación del MINECO HAR2011-27431 "La construcción política de los territorios romanos en la provincia Hispania Citerior (197 a.C.-69 d.C.)", encuadrado en el Grupo de Investigación Consolidado (B) del Gobierno Vasco IT760-13, cuyo IP es el Prof. Juan Santos.
} 
El título de nuestra comunicación señala con claridad los dos límites que nos hemos impuesto en nuestra intervención. El primero es el geográfico, ya que aquí nos centraremos únicamente en los tres conventus del Noroeste, el Asturicensis, el Lucensis y el Bracaraugustanus. El segundo se refiere al contenido, pues limitaremos nuestro análisis a un solo aspecto del gobierno del emperador Augusto, el que atañe directamente a las comunidades indígenas y a los cambios que se producen a partir de la conquista del Noroeste. Ahora bien, teniendo en cuenta que otros colegas ya han tratado aspectos administrativos, militares o económicos y el límite de páginas impuesto por los editores, no pretendemos ni mostrarlos todos ni teorizar sobre ellos. Presentaremos una selección de textos epigráficos y literarios que nos parecen suficientemente representativos para poner en evidencia, en la práctica, algunos de los cambios que consideramos especialmente relevantes en los ámbitos jurídico e institucional.

Antes de comenzar nuestro análisis, sin embargo, se impone una matización previa. Quisiéramos recordar que cuando hablamos del Noroeste estamos utilizando un criterio geográfico que parece unificarlo todo, cuando en realidad nos referimos a realidades étnicas e históricas muy diversas. Las dos o tres características comunes que podemos observar en todos estos territorios, como son la ausencia de urbanismo previo o el escaso desarrollo de su sistema político o de sus sociedades, son demasiado vagos, imprecisos y podrían aplicarse a otras áreas peninsulares; por poner un ejemplo cercano, a toda el área cantábrica del conventus Cluniensis. Por lo tanto no constituyen una especificidad propia. A poco que profundicemos en las características del Noroeste vemos cómo aflora rápidamente su diversidad, incluso en el área aparentemente más homogénea, la de los dos conventus de la Callaecia. Es cierto que ambas parecen compartir la misma cultura, la castrexa, pero los investigadores ya han dejado bien claras las notables diferencias en su evolución. ${ }^{2}$ A partir del s. II a.C. la parte meridional, la del futuro conventus Bracaraugustanus, tendrá un mayor desarrollo económico, con un aumento del artesanado y del comercio, acompañado de un aumento demográfico. Al mismo tiempo se documenta la reestructuración de su hábitat, dando lugar a entidades mayores que adquieren las características de auténticos oppida. Por último habrá incluso un mayor desarrollo artístico, que, si bien es bastante limitado si lo comparamos con otras áreas peninsulares, supone introducir decoraciones simples en los elementos arquitectónicos e, incluso, más adelante, algunas formas de estatuaria monumental. ${ }^{3}$

Si esto es así en el área culturalmente más homogénea, podemos comprender que las diferencias dentro del territorio que se atribuirá al conventus Asturicensis son mucho mayores, empezando por las geográficas, al unir pueblos de ambos lados de la cordillera Cantábrica. A las diferencias étnicas se añadirán las culturales, con la presencia de influencias castrexas en su área occidental, cántabras en la oriental y

2 Las reflexiones sobre la diversidad y complejidad del mundo castrexo se remontan al menos dos decenios; vid. el planteamiento teórico de Martins (1993-1994) y los estudios regionales de L. X. Carballo (1986; 1990).

3 Sobre los cambios en el área meridional de Callaecia, vid. especialmente SANDE Lemos 2009, Martins 2012; sobre la diferente evolución del castrexo y las diferencias entre el norte y el sur del territorio de esta cultura, vid. los trabajos de CALO 1997, 1997a y González Ruibal 2007. 
celtibéricas en la zona meseteña. A ello deberíamos añadir la ausencia de unidad organizativa que nos muestra la onomástica o la epigrafía, que menciona las gentilitates, gentes, y castella, de naturaleza y finalidad bien distintas. ${ }^{4} \mathrm{El}$ concepto Noroeste esconde, por tanto, un conjunto de pueblos que carecen de unidad étnica, cultural o geográfica, a la que, naturalmente, debemos añadir la política.

Con lo que acabamos de esbozar brevemente podemos comprender que lo que nos permite hablar genéricamente del Noroeste y abordarlo conjuntamente es su relación con Roma. Tienen en común que son sometidos tras las campañas llevadas a cabo, en parte personalmente, por el propio emperador Augusto. A diferencia de otras áreas peninsulares que durante la República sufrieron prolongadas campañas con sus avances y retrocesos -las celtibéricas o lusitanas del s. II a.C.--, la conquista del Noroeste fue brevísima, se realizó en menos de diez años, del 29 a.C. al 19 a.C. A partir de este momento se inicia un nuevo proceso histórico en que el Estado romano empezará a intervenir, en grados muy distintos, sobre las comunidades indígenas, para lograr su plena integración y hacerlas gobernables. Es cierto que seguirá sin haber homogeneidad en aquellos aspectos que no son imprescindibles para su control, y así nos lo seguirá mostrando la onomástica, el tipo de hábitat o las creencias expresadas en la religión indígena. ${ }^{5}$ Sin embargo, como resultado directo de la acción romana veremos una uniformización administrativa, cambios institucionales y jurídicos y nuevos elementos de cohesión como el culto imperial que, ahora sí, afectarán a todos los pueblos del Noroeste.

Es imposible analizar esas transformaciones de las sociedades indígenas en todas sus dimensiones, ya que la información que nos proporcionan las fuentes es, generalmente, imprecisa y parcial, como también lo es la investigación que se ha realizado sobre ellas.

Ejemplo de lo primero, de la parcialidad de las fuentes, son los datos que encontramos en las literarias. Como es habitual en las provincias occidentales del Imperio, los únicos escritos conservados son los romanos y sabemos que los pueblos y territorios les interesan a medida que entran en contacto con ellos, bien sea por motivos militares, económicos o estratégicos. El temprano contacto con otras áreas peninsulares supone, por ejemplo, disponer de alusiones a los celtíberos en Polibio, ya en el s. II a.C. mientras que en el Noroeste tendremos que esperar a la misma época de la conquista a finales del s. I a.C. Hasta entonces el silencio es prácticamente absoluto, con la excepción de breves referencias como las que Heródoto (3.115) o Diodoro de Sicilia (5.38) hacen sobre las riquezas de las Cassiterides en las que se puede ver una cierta relación con el Norte, o las de César (BC 1.38.3) con las alusiones a los pueblos que aportan tropas a las campañas militares. El panorama empieza a cambiar cuando el Noroeste empieza a formar parte del Imperio Romano y las menciones a estos te-

4 Sobre las diferencias onomásticas dentro del conventus vid. Albertos 1985 y De Hoz 2010; sobre los asentamientos y la cultura material, ESPARZA 1986, CARROCERA 1996, CELIS 1996; para el ámbito del castreño asturiano, MAYA 1989, FERNÁNDEZ OCHOA 1999 y FANJUL 2004, 2005; sobre las estructuras indígenas reflejadas en las inscripciones, vid. González 1986, 1999, SAntos 1985, 2009, González - SANTos 1994.

5 Sobre el hábitat y la onomástica vid. la bibliografía de las nn. 3 y 4 . El análisis del mundo religioso sigue presentando numerosos problemas de fuentes e interpretación de las mismas; para una puesta al día de esta cuestión y una visión general, vid. GonZÁLEz 2007 y LE Roux 2009. 
rritorios se incrementan, aunque sus contenidos, en lo que se refiere a nuestro tema, siguen siendo desalentadores y poco útiles.

Como es sabido, las referencias más extensas son las de Estrabón, lo cual tiene la ventaja de que han sido escritas justamente en época augustea, pero el inconveniente de la naturaleza de la obra, una Geografía muy marcada por los tradicionales conceptos griegos y, por tanto, con un férreo etnocentrismo. De este modo, si los turdetanos "a los que poco les falta para ser todos romanos" (3.2.15) merecen que se les dedique un capítulo entero del libro tercero, los pueblos del norte, con nombres ininteligibles (3.3.7) y que no siempre es necesario mencionar, son presentados de acuerdo con esta visión. La investigación ya se ha encargado en los últimos años de poner de manifiesto sus clichés y deformaciones en tantos aspectos -religión, sociedad, costumbres, entre otros- y no volveremos ahora sobre ello. ${ }^{6} \mathrm{Si}$ éste es el autor que escribe con mayor extensión sobre el Noroeste, podemos imaginar lo que hallamos en otras fuentes que tratan con mayor brevedad lo relativo a este territorio, en su mayoría centradas especialmente en la conquista, con breves notas sobre la administración o los asentamientos. Esto es lo que podemos ver en el s. I d.C. en autores como Floro o Plinio, y en el s. II d.C. con Dión Casio. Es difícil responder a partir de ellas a todas las cuestiones que nos surgen en torno a la naturaleza política de las comunidades, la implantación territorial o las estructuras de poder de los indígenas.

Como ejemplo de lo segundo, de los problemas de interpretación de las fuentes por parte de la investigación actual, tenemos la arqueología, que, en general, carece de estudios de conjunto. En la mayoría de los casos se carece de una mínima planificación de las excavaciones, que seleccione áreas, asentamientos o material que pueda ofrecernos información suficiente para sistematizar este mundo indígena. Generalmente disponemos de datos sueltos e inconexos, de distintas épocas y lugares. Seguimos actuando en términos provinciales (actuales), regionales y locales, por tanto en ámbitos reducidos y diferentes de los romanos. Así que en el conventus astur disponemos de análisis de la arqueología de los cántabros, de las tierras leonesas sobre todo en su vertiente de la minería del oro y, por otra parte, de aquellas que han sufrido las influencias celtibéricas, a las que se añaden las de los castros del occidente asturiano. ${ }^{7}$ Por citar un ejemplo concreto, esto supone que todavía hoy carecemos de estudios que nos muestren la modificación del hábitat en el Noroeste tras la conquista. No sabemos cómo han influido las nuevas vías, las ciudades o los cambios económicos en un hipotético traslado, desaparición o concentración de algunas entidades. ${ }^{8}$ A día de hoy ni siquiera podríamos explicar qué ha pasado con las decenas de castros que rodean la nueva ciudad de Lucus Augusti con la excepción de uno, Agra dos Castros,

6 Sobre esta cuestión son ya clásicos los trabajos de Bermejo Barrera que aparecen citados en la bibliografía final. Sobre el conocimiento geográfico de la península y los problemas historiográficos, vid. CRUZ ANDREOTTI 2007.

7 Vid. la bibliografía de la n. 4. Sobre las áreas de explotación minera, vid. los trabajos de SÁNCHEZPALENCIA 1983, 2002.

8 Solo en el caso de Bracara Augusta tenemos estudios sobre el territorio circundante, el primero de MARTINS 1990, y el de CARVALHO 2008, con la nueva estructuración catastral. 
situado a menos de dos kilómetros del núcleo amurallado. ${ }^{9}$ En él se realizó tan solo una excavación de emergencia limitada a sondeos en cuatro zonas bien delimitadas por donde debía pasar la canalización del agua. La modificación de su estructura es obvia, con la destrucción de sus murallas simultáneamente a la construcción de la nueva capital romana, pero no podemos decir más sobre los cambios en sus estructuras sociales o económicas.

Después de mostrar los problemas a los que nos enfrentamos a la hora de buscar información sobre nuestro tema en estas dos fuentes básicas, deberíamos temernos lo peor al considerar la tercera relevante, la epigrafía, y, sin embargo, aquí somos unos privilegiados. Es verdad que, a diferencia de otras áreas peninsulares que tuvieron sus propios sistemas de escritura, en el Noroeste estamos hablando de sociedades ágrafas. Los indígenas no conocen la escritura y no disponemos de "Bronces de Botorrita", ni nada similar. La epigrafía aparece al tiempo que se produce la conquista y la extensión del hábito epigráfico es un lento proceso, por lo que las inscripciones realizadas por indígenas de época julio-claudia e incluso flavia son escasísimas. ${ }^{10}$ Hay, sin embargo, un factor extraordinariamente importante, pues, si apenas disponemos de documentos indígenas, se conservan, en cambio, otras inscripciones que son documentos oficiales o inspirados por el poder, absolutamente excepcionales, únicos en la historia peninsular. ${ }^{11}$ El bronce de Bembibre con el "Edicto de Augusto", datado en Narbona en el 15 a.C., la Tabula Lougeiorum, del 1 d.C., realizada entre C. Asinio Galo y los Lougei, las dedicaciones de P. Fabio Máximo, tres localizadas en Lugo (IRPLugo 19, 20 y, quizás, $21^{12}$ ) y otra cerca de Braga (EE VIII, $280=I L E R$ 1028), todas ellas de época de Augusto. Todas tienen en común su temprana datación, su excelente estado de conservación y la valiosísima información que muestra la intervención tan intensa a la que fueron sometidos las tierras y los pueblos del Noroeste inmediatamente después de su conquista. Con ellas sí disponemos de información sobre las modificaciones de las civitates indígenas y la implantación de las provincias, la creación de los conventus iuridici y la expansión del culto imperial por el Noroeste.

Los dos primeros documentos que mostraremos son el Edicto de El Bierzo y la Tabula Lougeiorum. ${ }^{13}$ Como es sabido, ambos son dos tabulae de bronce, escritas en latín, con un texto perfectamente conservado y datadas con precisión en época de Augusto, la primera en el 15 a.C., la segunda el 1 d.C. No las analizaremos en pro-

\footnotetext{
9 Sobre los castros de alrededor vid. el catálogo de GonZÁLEZ FernáNDEZ - FerRER SIERRA 1996; sobre las conclusiones que se pueden extraer de la limitada excavación de Agra dos Castros, Bartolomé 2009.

10 Como puede verse en los distintos corpora editados hasta el momento: Álvarez Blázquez - Bouza Brey 1961; Bouza Brey - D’Ors 1949; Vázquez Saco - Vázquez Seijas 1954; Filgueira Valverde - D’Ors 1955; Vázquez Saco 1958-59; Del Castillo, D’Ors 1959; Lorenzo Fernández - Bouza Brey 1965; Lorenzo Fernández 1968 y, más recientemente, Arias - Le RouX - Tranoy 1979; Pereira Menaut 1991 y BAÑos 1994.

11 Es lo que Pereira Menaut (1995) ha denominado "epigrafía política”, aquella realizada o inspirada desde el poder.

12 Cabe esta posibilidad, aunque, siendo una inscripción fragmentaria y estando actualmente desaparecida, en ausencia de una verificación directa, Arias, Le Roux y Tranoy $(1979,45)$ afirman que "hay que considerar el texto con extrema prudencia".

13 El texto del Edicto y la interpretación que seguiremos es el establecido por ALFöLDY 2001; para la Tabula Lougeiorum vid. Dopico CAínzos 1986.
} 
fundidad, pues ya han sido debidamente estudiadas, únicamente nos detendremos en ciertas cuestiones que muestran la naturaleza e intensidad de los cambios.

Entre las dos tenemos perfectamente documentada la primera consecuencia de la conquista sobre las comunidades indígenas, la pérdida de su independencia política y su inserción en un marco administrativo nuevo, el de las civitates, conventus y provincias, creado por Roma y que no respeta necesariamente la realidad anterior. No es algo específico del Noroeste, porque encontramos el mismo proceso en toda Hispania; ahora bien, hay varios factores que lo hacen más complejo.

En la primera parte del texto del Edicto de El Bierzo encontramos la recompensa que el emperador otorga a una comunidad indígena que ha sido fiel a Roma y ratifica los límites de su civitas, permitiéndole, añade, que continúe con los que poseía durante el gobierno de L. Sestio Quirinal. No sabemos cuáles eran estos límites, si coincidían o no con los previos indígenas o habían sido modificados, pero, en cualquier caso, hay algo que queda muy claro, no estamos ante un asunto indígena, sino romano. El texto señala cuál era la autoridad que sancionaba y legitimaba los límites, el gobernador, quien lo hace en nombre de Roma. Esto nos retrotrae a alguna fecha situada entre los años 22 a 19 a.C.; al menos desde entonces las nuevas civitates serían operativas, ya se habrían fijado los límites, los habrían registrado y controlado. ${ }^{14}$ Pero no podemos olvidar que en esa época todavía había actividad militar; recordemos que ésta se extendió desde el 29 a.C. hasta el 19 a.C. y, desde entonces, todavía habrá algunas intervenciones menores destinadas a la pacificación de algunos pueblos del norte. Esto implica una transformación muy rápida, nos permite suponer que, a medida que se pacifican los territorios, se empiezan a adaptar a la nueva situación, sin que sea necesario esperar a la total conclusión de la guerra, y esto no deja de ser sorprendente tratándose del Noroeste. Estamos hablando de territorios mucho menos conocidos en comparación con el resto de la península. Aunque las situaciones son muy diversas, no podemos obviar que el litoral mediterráneo fue objeto de exploraciones geográficas y de contactos de distinta intensidad, desde los simples comerciales hasta los coloniales, que los asentamientos significativos de población itálica, generalmente con fines comerciales, se inician ya en el s. II a.C. (recordemos, por ejemplo, los sectores vinculados a la explotación económica de Carthago Nova, o los de Tarraco). ${ }^{15}$ Incluso amplias regiones del valle del Ebro, de la Meseta o de la futura Lusitania fueron objeto de campañas militares prolongadas y el conocimiento,

14 Imp(erator) Caesar Divi fil(ius) Aug(ustus) / trib(unicia) pot(estate) /VIII[I] et pro co(n)s(ule) dicit: Castellanos Paemeiobrigenses ex / gente Susarrorum desciscentibus / ceteris permansisse in officio cog/ novi ex omnibus legatis meis, qui / Transdurianae provinciae prae/ferunt. Itaque eos universos im/munitate perpetua dono; quosq(ue) / agros et quibus finibus possede/runt Lucio Sestio Quirinale leg(ato) / meo eam provinciam optinente $[\mathrm{m}]$ / eos agros sine controversia possi/dere iubeo. Castellanis Paemeiobrigensibus ex / gente Susarrorum, quibus ante ea / immunitatem omnium rerum dede/ram, eorum loco restituo castellanos / Aiiobrigiaecinos ex gente Gigurro/rum volente ipsa civitate; eosque / castellanos Aiiobrigiaecinos om/ni munere fungi iubeo cum / Susarris. Actum Narbone Martio XVI et XV K(alendas) Martias / M(arco) Druso Li/ bone, Lucio Calpurnio Pisone / co(n)s(ulibus).

15 Las dos tienen magníficos puertos, que permiten intensas relaciones comerciales, y riquezas naturales que, en el caso de Carthago Nova, se extienden más allá de las actividades agrícolas con las explotaciones mineras. Sobre la implantación de itálicos y su origen, establecido a partir de la onomástica, vid. Koch 1988, ABASCAL 1997; sobre Tarraco, AlFöLDY 1991. 
siquiera parcial, del terreno y de sus pueblos se había producido con anterioridad a la conquista.

La situación del Noroeste es diferente, aunque no de aislamiento absoluto. Las campañas de D. Junio Bruto (138 a.C.) o de César (61-60 a.C.) abrieron el camino a contactos comerciales y a transformaciones internas de las comunidades, llevando a una diferente evolución entre el norte y el sur de Callaecia, como ya hemos comentado. Sin embargo, aparte de esto, no tenemos noticia de que hubiese una fuerte implantación de elementos romanos o itálicos con anterioridad a la conquista y, para encontrar una expresión tan clara con la mención de los cives Romani qui negotiantur Bracara Augusta, debemos esperar a época claudia. ${ }^{16}$ Tampoco ha habido campañas militares de una cierta extensión, más allá de las mencionadas, ni tenemos noticias de exploraciones geográficas ni de obras de esta naturaleza. Debemos suponer, por tanto, que el conocimiento en profundidad del territorio únicamente se realiza tras la conquista, que es entonces cuando mejor se conoce la entidad o el tamaño de sus pueblos, sus límites, su población o cuáles son las mejores comunicaciones entre ellos y hacia el exterior. La labor de los distintos gobernadores provinciales y de otros funcionarios que recorrieron el territorio debió ser significativa, como sin duda lo fue el papel de Agripa, cuyo interés por el control del espacio es bien conocido. ${ }^{17}$

Antes de finalizar el s. I a.C. ya estaban implantadas las formas básicas de administración bien conocidas en las provincias occidentales del Imperio, que suponen una modificación estructural de las comunidades indígenas. Roma registrará los nombres colectivos de las civitates, les otorgará nuevas funciones desconocidas para los indígenas, como el cobro de impuestos y la realización del censo, y fijará sus límites, que, como acabamos de señalar, dependen de sus intereses y no tienen por qué coincidir con realidades previas.

La segunda tabula nos permite completar los cambios institucionales con la mención de los conventus iuridici. ${ }^{18}$ De nuevo nos encontramos ante un proceso complejo, más que los anteriores, porque esta división territorial se implanta ahora por primera vez. Había que decidir cuántos se crearían en el Noroeste, qué pueblos quedaban adscritos a cada uno y, por tanto, cuáles eran los límites geográficos que deberían tener, dónde se situaban sus ciudades capitales para ser fácilmente accesibles y cómo se establecían las vías que permitirían un adecuado acceso del gobernador desde Tarraco. El análisis de las soluciones nos muestra, una vez más, el acierto con el que se realizaron. Se tuvieron en cuenta factores demográficos para facilitar un número similar de población, lo cual a su vez supuso controlar los pueblos que se integraban en ellos. Sus tres capitales demostraron estar situadas en los lugares idóneos

16 C(aio) Ca\{́t\}ronio C(ai) [f(ilio)] / Cam(ilia) Miccioni tri(buno) / pl(ebis) pr(aetori) legato Aug(usti) [Hisp(aniae)] / c[ite]rioris leg(ato) (...) (CIL II, 2423); vid. ALFöLDY 1966 para su interpretación histórica.

17 Rodá (1998) ya puso de manifiesto el importante papel de Agripa en la reorganización de Hispania; en cuanto a su obra, en general, vid. la extensa monografía RoDDAz 1986. Para analizar la importancia del dominio y conocimiento del espacio, especialmente en época de Augusto, vid. NicOLET 1988.

18 C(aio) Caesare Aug(usti) f(ilio) L(ucio) Aemilio Paullo co(n)s(uibus) / Ex gente Asturum conventus Arae / August(a)e / civitas Lougeiorum hospitium fecit cum / C(aio) Asinio Gallo libereis postereisque eius / eumque liberos posterosque eius sibi libe/reis postereisque suis patronum cooptarunt / isque eos in fidem clientelamque suam suo/rumque recepit/ Egerunt legati / Silvanus Clouti / Noppius Andami. 
para que indígenas que habitasen en cualquier lugar del conventus pudiesen llegar a ellos, se eligió una buena solución estratégica al fragmentar los pueblos enfrentados anteriormente, dejando parte de los cántabros en el Cluniensis y parte en el Asturicensis, y se favoreció la integración de los pueblos transcantábricos y meseteños. La Tabula Lougeiorum, nos muestra que todo ello ya estaba en marcha cuanto menos en el 1 d.C., si bien todavía quedaban por realizar cambios significativos. ${ }^{19}$

No nos hemos referido directamente a una tercera instancia administrativa que también aparece en el Edicto de El Bierzo, la provincial. Ya habrá sido tratada en otras ponencias y no es nuestra intención volver sobre ello. Solo queremos insistir en que la creación de una nueva administración en todas sus instancias, desde las más elementales de las civitates hasta las provincias, fue un proceso complejo. El hecho de que Augusto hubiese realizado al menos dos propuestas diferentes para situar Callaecia hasta dejarla en la Citerior no es una muestra de improvisación ni de arbitrariedad. Por el contrario, indica que se buscaba una razón administrativa sólida y no se dudó en experimentar con distintas soluciones hasta que se encontró la considerada idónea.

Los dos documentos epigráficos examinados nos indican que apenas 20 años después de finalizada la conquista, y sobre un territorio peor conocido que el resto peninsular, ya se había completado o, en su caso, avanzado en la estructura básica de la administración romana y, con ella, se habían producido numerosos cambios y transformaciones jurídicas, institucionales, sociales, de una intensidad destacable. Las más evidentes son la pérdida de la independencia de las comunidades indígenas que quedan con una simple autonomía local bajo la forma de civitates, lo que supone perder la capacidad de decidir su política hacia las comunidades vecinas en función de sus propios intereses, su capacidad coercitiva en favor del ejército romano del que pueden llegar a formar parte como auxilia. Es Roma quien, según sus intereses, les fija sus límites y decide la pertenencia de los individuos a cada grupo, que puede ser distinto del que ha sido secularmente el de su familia.

Pierden igualmente su capacidad normativa en aspectos esenciales, pues, aunque sus formas de derecho fuesen básicas y consuetudinarias, ahora serán juzgados por el gobernador provincial o sus legatus iuridici siguiendo la ley romana y en una lengua ajena, el latín. Todas las normas que rigen la celebración de los conventus, desde el día de su celebración, la duración, las fórmulas jurídicas y el lugar en el que se celebra, son decididas por Roma. Esto supone que a algunos miembros de estas comunidades se les obliga a conocer y a reconocer la nueva ciudad que no ha sido concebida como un núcleo poblacional para instalar veteranos o población itálica, sino como una sede permanente y más cercana que Tarraco, la capital provincial, que estará siempre presente como tal ante los ojos de los indígenas.

Hasta aquí hemos visto los cambios forzosos, impuestos desde arriba, por la parte más fuerte, la romana, pero no podemos dejar de mencionar las transformaciones que asume la otra parte, la indígena, en su emulación de Roma. La atracción y utilización de las elites fue secularmente realizada por el Estado romano en su expansión. Solo

19 Sobre la constitución territorial de los conventus y la adecuada elección de cada capital tanto interna como en relación al recorrido del gobernador, vid. DopICO - SANTOS 2012 y e.p. 
mencionaremos aquí tres documentos epigráficos que nos muestran esta emulación sobre todo en su vertiente institucional.

Una de las inscripciones más llamativas encontradas en Lugo es la que menciona al princeps Copororum. Este título no es excepcional en la epigrafía peninsular, ya que conocemos otras inscripciones que bajo esta mención latina hacen referencia a elites de las comunidades sin que esto implique ninguna precisión institucional. ${ }^{20}$ Ahora bien, quisiéramos llamar la atención sobre algunos aspectos de ésta, empezando por el soporte y otras cuestiones formales. La inscripción fue realizada sobre un enorme bloque de granito actualmente fragmentando, por lo que, aunque en la actualidad mide $48 \times 110 \times 25 \mathrm{~cm}$, le faltan al menos unos $20 \mathrm{~cm}$ de lado. Es un tamaño considerable, como también lo es su peso actual, alrededor de $100 \mathrm{~kg}$, lo que, dentro de los parámetros indígenas del Noroeste, la convierten en una inscripción excepcional y monumental. El tamaño de las letras también es notable, entre 7 y $8 \mathrm{~cm}$, aunque lo más destacable es que estemos hablando de una capital perfecta, como también lo es su ordinatio. ${ }^{21}$ Para comprender mejor la diferencia podemos compararla, por ejemplo, con la tabula de El Caurel, de factura más deficiente en la letra y en la ordinatio o, por buscar un texto similar, con la del princeps Albionum, igualmente mucho más tosca y simple en su soporte y letra. ${ }^{22}$ Lamentablemente, como hemos comentado, la inscripción está fragmentada, lo que impide leerla en toda su extensión; sin embargo la interpretación de este princeps como perteneciente al pueblo de los Copori, que, según Ptolomeo (2.6.23), ocupaba el territorio de Lucus Augusti, es bastante probable.

También parece segura la alusión a otro princeps de la Hispania Citerior, aunque, en este caso, no tengamos la correspondiente alusión étnica. La inscripción no ha podido ser datada con precisión, pero se cree que sería temprana, de la primera mitad del s. I d.C., lo que nos muestra la rapidez con la que sus elites adoptan ciertas formas romanas. La onomástica es totalmente indígena, pero tienen el cuidado de encargar una inscripción que, en su forma, su ordinatio y su letra es digna del ambiente urbano que representa la capital conventual, Lucus Augusti, y se aleja radicalmente de otras indígenas de ambiente rural. El princeps que vivía en una ciudad de pleno urbanismo romano, con importantes sectores administrativos, se distancia con claridad del que habita en el campo al norte del conventus. Se cuida igualmente la mención de las unidades administrativas, con una precisa alusión a las divisiones provinciales (Provin-

20 Por ejemplo, en el propio norte peninsular, princeps Albionum (Vegadeo, Asturias. Nicer / Clutosi / c(astello) Cari/aca / princi/pis Al/bio/nu/m an(norum) / LXXV / hic s(itus) est. ERA 14; AE 1946, 121), princeps Arcael(on?) (Paredes de Nava, Palencia. Cisaros Cecciq(um) pr(inceps) / Arcailo(n). CIL II, 5762) o princeps Cantabrorum (Valamartino, León. Dovide/rus Ampa/rami f(ilius) pr/inceps Can/tabroru/m h(ic) s(itus) e(st)... MANGaS - Martino 1997, 326). Sobre este tema vid. últimamente SANTOS - Dopico (e.p.).

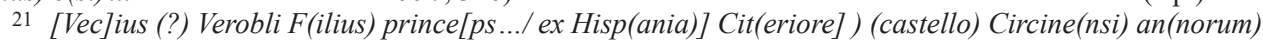
$L X$ [et /Vecc]o (?) Veci F(ilius) (...) princeps Co[pororum (?)] / an(norum (?) h(ic) s(iti) sunt heredes sib[i et suis] / f(aciendum) c(uraverunt). Seguimos la lectura de IRPLugo 34.

22 Appio Iunio Silano P(ublio) Silio / Nerva co(n)s(ulibus) / Tillegus Ambati f(ilius) Susarrus / (castello) Aiobrigiaeco hospitium / fecit cum Lougeis castellanis / Toletensibus sibi uxori libe/ris posterisque suis eumq/ ue uxorem liberosque eius / in fidem clientelamque sua/m suorumque in perpetuo cas/tellanei Toletensis receperunt / Egit Tillegus Ambati ipse / mag(istratibus) Latino Ari (filio) et Aio Temari (filio) (IRPLugo 55). Para la inscripción de Nicer vid. nota 20. 
cia Hispania Citerior) y a los castella respectivos. Estos indígenas escogen el latín, las fórmulas y las titulaturas de Roma y olvidan las indígenas -cualquiera que fuese su denominación- $\mathrm{y}$, manteniendo sus bases económicas y de prestigio social intactas, se trasladaron a vivir a la nueva ciudad. No sabemos cuál sería su papel político, pero probablemente sería relevante. Hay otras tres inscripciones que profundizan un poco más en la asimilación indígena de las formas institucionales romanas.

Hemos recordado que Roma respeta la autonomía interna de las civitates peregrinae y, en principio, no impondría sus propias formas de gobierno, magistraturas o instituciones. Para encontrar cambios significativos debemos esperar a la época flavia con la donación del ius Latii, cuando asistimos al abandono paulatino de los castros y a la adopción de magistraturas romanas, sin que ello implique la urbanización de sus centros políticos como bien pone de manifiesto el duovir M. Flavio Sabino, de los límicos (CIL II, 4215). ${ }^{23}$ Sin embargo, algunos documentos, como son las tablas de hospitalidad de los Lougei, de El Caurel y la de los Zoelae, nos muestran una asimilación muy temprana de las formas romanas.

Aunque la tabula de los Lougei contiene un pacto aparentemente realizado por iniciativa indígena, la inspiración romana, como en tantos otros documentos, es evidente. Un texto realizado en latín en el año 1 d.C., con las fórmulas habituales de la epigrafía latina no tuvo su origen en una comunidad del Noroeste, como tampoco ese contenido que los vincula al Estado romano de forma indirecta, a través de su gobernador. No podemos ahora detenernos en todas las cuestiones relevantes, solo queremos fijarnos en su final, en donde se menciona a dos indígenas con la estructura del nombre todavía muy sencilla (nombre más filiación) pero ya latinizada: Silvano hijo de Clouto y Nopio hijo de Andamo. Reciben la denominación latina de legati, algo que sería totalmente desconocido para ellos, pero que es común a otras tabulae hospitales. Era, evidentemente, un procedimiento romano el que marcaba el protocolo de cómo transmitir estos pactos a los interesados. En la ley municipal de Urso se establecen las normas sobre el procedimiento de elección de los legati y se indica que debe hacerse entre las elites del ordo decurional. ${ }^{24}$ Aunque aquí no existiera una institución similar, parece evidente que los legati de los Lougei que entregarían el pacto al gobernador pertenecían a las elites de su comunidad y que adoptan -o se les hace adoptar- una denominación institucional que era ajena a ellos. ${ }^{25}$

La segunda tabula, la de El Caurel, presenta un contexto plenamente indígena, ya que ambas partes contrayentes lo son, tanto Tilegus, hijo de Ambatus, como el castellum de los Toletenses de la civitas de los Lougei. Como ya hemos señalado, su letra y la ordinatio no son especialmente buenas y difieren claramente de la anterior en la que la parte romana ha impuesto la realización de un documento óptimo desde el punto de vista del contenido y de la forma. De nuevo queremos fijarnos en su parte final, aquella en la que se menciona que se realizó siendo magistrados Latino, hijo de Aro, y Aio, hijo de Temaro. La onomástica y la estructura del nombre vuelven a ser

23 Sobre la transformación de las comunidades vid. Pereira Menaut - Santos 1980.

24 En su capítulo 92 se menciona cómo se eligen los legati que representan a la comunidad. Sobre su función y nombramiento vid. Rodríguez NeILA - SANTERo SANTURINo 1982,134 ss.

25 Rodriguez NeILA 1998, 123. 
indígenas, pero es muy significativa la utilización del cognomen Latinus para designar a uno de los magistrados, lo que ha sido interpretado como un evidente signo de acercamiento al poder romano. Además se menciona a dos magistrados, con lo que parece evidente el paralelo entre esa fórmula final y la de los dos cónsules iniciales, de modo que funcionarían igualmente como magistrados epónimos, los principales de la comunidad. ${ }^{26}$

El último documento al que queremos referirnos es la tabula de los Zoelae. Su primera parte, la de datación más temprana, nos muestra la pervivencia del contexto indígena, al precisar que el pacto se realiza en Curunda, que probablemente sería el centro de la gens Zoelarum. Todos los contrayentes del pacto tienen onomástica indígena, con la fórmula igualmente indígena de la estructura nominal de un solo elemento y su filiación en genitivo. Al final, sin embargo, encontramos una vez más la mención de un magistrado, que, a pesar de tener la misma estructura nominal que los anteriores - per Abienum Pentili-, asume una denominación puramente latina: magistratum Zoelarum. ${ }^{27}$

En los tres casos estamos ante documentos tempranos en los que el tipo de soporte, la lengua, las fórmulas, el contenido, la onomástica y las titulaturas muestran el interés de las elites indígenas por imitar las formas romanas. Cuando Polibio (10.36) analizaba las causas de la pérdida de apoyos de Cartago en la península, aludía a su cambio de actitud hacia sus aliados indígenas y afirmaba: "Se ha demostrado muchas veces, y muy claramente, que los hombres logran el poder si tratan con benignidad e infunden esperanzas a sus vecinos". Ciertamente, como hemos visto a lo largo de este trabajo, Roma supo combinar la naturaleza imperativa de algunos de sus cambios con el estímulo a la asimilación de las elites y el mantenimiento de sus privilegios que le permitió utilizarlas a su favor. Esto explicó, en gran medida, la aceptación de su imperio por los pueblos conquistados.

\section{BibLIOGRAFÍA}

AAVV. (2006): Colonia Iulia Urbs Triumphalis Tarraco, Tarragona.

Abascal Palazón, J. M. - Ramallo Asensio, S. F. (1997): La ciudad de Carthago Nova: la documentación epigráfica, Murcia.

ALFöLDY, G.

(1991): Tarraco, Tarragona.

(2001): "El nuevo edicto de Augusto de El Bierzo en Hispania", [en] L. Grau - J. L. Hoyas (eds.), El bronce de Bembibre. Un edicto del emperador Augusto, León.

Albertos, $\mathrm{M}^{\mathrm{a}}$ L. (1987): "La onomástica personal indígena de la región septentrional”, [en] Actas del IV Coloquio sobre lenguas y culturas paleohispánicas (Vitoria 1985), Vitoria, 155-194.

Álvarez Blázquez, J. M. - Bouza Brey, F. (1961): "Inscripciones romanas de Galicia. Suplemento al fasc. III. Vigo", CEG 48-5-42.

26 Arias Vilas - Le Roux - Tranoy 1978,75-78, n55.

27 Sigue siendo válida la interpretación de este documento ofrecida por J. Santos $(1985,5 \mathrm{ss})$. 
Arias Vilas, F. - Le Roux, P. - Tranoy, A. (1979): Inscriptions romaines de la province de Lugo (=IRPLugo), Paris.

Baños Rodríguez, G. (1994): Corpus de inscricións romanas de Galicia. II. Provincia de Pontevedra, Santiago de Compostela.

Bartolomé Abraira, R. (2009): “O castro da Piringalla e a sua relación con Lucus Augusti”, [en] M D. Dopico Caínzos - P. Rodríguez - M. Villanueva Acuña (eds.), Do Castro á cidade. A Romanización na Gallaecia e na Hispania indoeuropea, Lugo, 143-177.

BERMEJo BARRERA, J. C.

(1979): “Tres notas sobre Estrabón: Sociedad, Derecho y Religión en la cultura castreña”, Gallaecia 4, 71-97.

(1983): "El erudito y la barbarie: La construcción de la realidad etnográfica galaica prerromana en la Geografía de Estrabón", [en] I Xornadas de Historia de Galicia, Ourense, 3-21. (1983): "Etnografía castreña e Historiografía Clásica", [en] G. Pereira Menaut (ed.), Estudos de cultura castrexa e Historia Antigua de Galicia, Santiago de Compostela, 129-146.

CAlo Lourido, F.

(1997): “A síntesis: o galaico-romano", [en] G. Pereira Menaut (ed.), Galicia fai dous mil aos. O feito diferencial galego, Santiago, 193-212.

(1997a): A cultura castrexa, Vigo.

(2010): Os celtas. Unha (re)visión dende Galicia, Vigo.

Carballo Arceo, L. X.

(1986): Povoamento castrexo e romano da terra de Trasdeza, Santiago.

(1990): "Los castros de la cuenca media del río Ulla y sus relaciones con el medio físico", Trabajos de Prehistoria 47, 161-199.

Carrocera Fernández, E. - Camino Mayor, E. (1996): "La Edad del Hierro en el territorio histórico de los astures o la realidad de un espacio administrativo romano", [en] C. Fernández Ochoa (coord.), Los finisterres atlánticos en la Antigüedad. Época Prerromana y romana, Madrid, 57-60.

Carvalho, H. P. A. (2008): O povoamento romano na fachada occidental do conventus bracarensis, Braga.

Celis SÁnchez, J. (1996): “Origen, desarrollo y cambio en la Edad del Hierro de las tierras leonesas", ArqueoLeón. Historia de León a través de la arqueología, Valladolid-León, 41-67.

Cruz Andreotti, G. - Le Roux, P. - Moret, P. (eds.) (2007): La invención de una geografía de la Península Ibérica: La época imperial, Málaga, 271-304.

De Hoz, J. (2010): "Las lenguas del Noroeste peninsular y la relación entre astures y galaicos", Larouco 5, 17-38.

Dopico CAínzos, Ma D. (1988): La Tabula Lougeiorum. Estudios sobre la implantación romana en Hispania, (=Anejos de Veleia 5), Vitoria.

Dopico Caínzos, Ma D. - Santos Yanguas, J. (2012): "La adecuación de las entidades indígenas a la nueva administración romana: el ejemplo de los "conventus" del Noroeste peninsular", [en] J. Santos Yanguas - G. Cruz Andreotti (eds.), Romanización, fronteras y etnias en la Roma antigua: el caso hispano, Revisiones de Historia Antigua VII, VitoriaGasteiz, 581-600.

(e.p.): "La creación de la red de ciudades conventuales de la Citerior", Revista de Historiografía. 
ESPARZA Arroyo, A.

(1983): "Problemas arqueológicos de la Edad del Hierro en el territorio astur", Lancia 1, 83-101.

(1986): Los castros de la Edad del Hierro del Noroeste de Zamora, Zamora.

Fanjul Peraza, A. (2005): Los castros de Asturias, una revisión territorial y funcional, Teverga.

Fanjul Peraza, A. - Menéndez Bueyes, L. R. (2004): El complejo castreño de los astures transmontanos, Salamanca.

Fernández OchoA, C. - Morillo Cerdán, A. (1999): La tierra de los astures. Nuevas perspectivas sobre la implantación romana en la antigua Asturia, Gijón.

GonzÁlez Fernández, E. - Ferrer Sierra, S. (1996): "Sustrato poblacional prerromano del entorno de Lucus Augusti”, [en] A. Rodríguez Colmenero (ed.), Lucus Augusti. El amanecer de una ciudad, vol. I, A Coruña, 329-418.

GonzÁlez RodríGuez, $\mathrm{M}^{\mathrm{a}} \mathrm{C}$.

(1986): Las unidades organizativas indígenas del área indoeuropea de Hispania, (=Anejos de Veleia 2), Vitoria-Gasteiz.

(2005): "Sobre la religio de los pueblos del NO durante el Alto imperio: algunas observaciones", Acta Palaeohispánica IX, (Actas del IX coloquio sobre lenguas y culturas palaeohispánicas, Barcelona 20-24 de octubre de 2004), (=Palaeohispánica 5), 709-720.

GonzÁlez Rodríguez, Ma C. - SAntos Yanguas, J. (eds.) (1994): Las estructuras sociales indígenas del Norte de la Península Ibérica, (Revisiones de Historia Antigua I), Vitoria.

González Ruibal, A. (2007): Galaicos. Poder y comunidad en el Noroeste de la Península Ibérica (1200 a.C.-50 d.C.), 2 vol., (=Brigantium 19), A Coruña.

Koch, M. (1988): "Las grandes familias en la epigrafía de Carthago Nova", [en] G. Pereira Menaut (ed.), Actas del I Congreso Peninsular de Historia Antigua, Santiago, 403-407.

LE Roux, P.

(1982): L'Armée romaine et l'organisation des provinces ibériques d'Auguste à l'invasion de 409, Paris.

(2003): “À la recherche des élites locales: Le Nord-Ouest hispanique”, [en] M. CébeillacGervasoni - L. Lamoine (eds.), Les élites et leurs facettes. Les élites locales dans le monde hellenistique et romain, (Coll. De l'École Française de Rome 309), Roma, 171-186.

(2009): “Cultos y religión en el noroeste de la península ibérica en el Alto Imperio romano: nuevas perspectivas", Veleia 26, 265-285.

Mangas, J. - Martino, D. (1997): “Princeps Cantabrorum en una nueva inscripción”, Gerión $15,321-339$.

MARTINS, M.

(1990): O povoamento proto-histórico e a romanização da bacia do curso médio do Cávado, (=Cadernos de Arqueología Monografias 5), Braga.

(1993-1994): "Continuidade e mudança no I milenio a.C. no Noroeste Português. Os diferentes cenários de representaçao do discurso arqueológico", Cadernos de Arqueologia, Série II, 10-11, 41-64.

Martins, M. - Ribeiro, J. - Magalhães, F. - Braga, C. (2012): "Urbanismo e Arquitetura de Bracara Augusta. Sociedade, economia e lazer", [en] Ma do Carmo Ribeiro - A. Sousa Melo (eds.), Evolução da paisagem urbana: sociedade e economía, Braga, 29-68. 
Martins, M. - Lemos, F. S. - PÉRez Losada, F. (2005): “O povoamento romano no território dos galaicos bracarenses", [en] Actas do Colóquio Internacional Unidad y Diversidad en el Arco Atlántico, Gijon, 279-296.

Maya González, J. L. (1989): Los castros en Asturias, Gijón.

Nicolet, C. (1988) : L'Inventaire du monde: géographie et politique aux origines de l'Empire Romain, Paris.

Pereira Menaut, G.

(1983): "Las comunidades galaico-romanas. Hábitat y sociedad en transformación”, [en] G. Pereira Menaut (ed.), Estudios de Cultura Castrexa e de Historia Antiga de Galicia, Santiago de Compostela, 199-213.

(1984): "La formación histórica de los pueblos del Norte Peninsular: el caso de Gallaecia como paradigma", Veleia 1, 271-287.

(1991): Corpus de inscricións romanas de Galicia. I. Provincia de A Coruña, Santiago de Compostela.

(1995): "Epigrafía “política” y primeras culturas epigráficas en el Noroeste de la Península ibérica”, [en] F. Beltrán (ed.), Roma y el nacimiento de la cultura epigráfica en Occidente, Zaragoza, 293-326.

Pereira Menaut, G. - Santos Yanguas, J. (1980): "Sobre la romanización del Noroeste de la Península Ibérica. Las inscripciones con mención del origo", [en] Actas del I Seminario de Arqueología del Noroeste Peninsular, vol. III, Guimarâes, 117-137.

RodÁ DE LlanzA, I. (1998): "El papel de Agripa en la trama urbana de la Hispania Augustea", [en] A. Rodríguez Colmenero (ed.), Los orígenes de la ciudad en el Noroeste hispánico, Lugo, 275-294.

Roddaz, J. M. (1984): Marcus Agrippa, Paris.

Rodríguez Neila, J. F. (1998): "Hispani Principes. Algunas reflexiones sobre los grupos dirigentes de la Hispania prerromana", Cuadernos de Arqueología 6, 99-137.

Rodríguez Neila, J. F. - Santero Santurino, J. M. (1982): "Hospitium y patronato sobre una tabla de bronce de Cañete de las Torres", Habis 13, 105-164.

Sánchez-Palencia Ramos, F. J.

(1983): "Las explotaciones auríferas y la ocupación romana del noroeste de la Península Ibérica", [en] Actas del II Seminario de Arqueología del Noroeste: Santiago de Compostela, 1980, Madrid, 225-246.

(2002): "Los castros y la ocupación romana en zonas mineras del Noroeste de la Península Ibérica", [en] M. A. de Blas Cortina - A. Villa Valdés (eds.), Los poblados fortificados del noroeste de la Península Ibérica: formación y desarrollo de la cultura castreña. Coloquios de Arqueología en la cuenca del Navia: homenaje al Prof. Dr. José Manuel González y Fernández-Valles, Navia, 241-259.

SANDE Lemos, F. (2009): "A transformaçao do habitat e da paisajem castreja no contexto da romanização: o exemplo dos grandes castros", [en] Mª D. Dopico Caínzos - P. Rodríguez - M. Villanueva Acuña (eds.), Do Castro á cidade. A Romanización na Gallaecia e na Hispania indoeuropea. Actas do curso de actualización sobre a romanización de Galicia, Lugo, 109-141.

SANTOS YANGUAS, J.

(1985): Comunidades indígenas y administración romana en el noroeste hispánico, Bilbao. 
(2009): "Las organizaciones indígenas en el Norte peninsular y la romanización", [en] Mª D. Dopico Caínzo - P. Rodríguez - M. Villanueva Acuña (eds.), Do Castro á cidade. A Romanización na Gallaecia e na Hispania indoeuropea. Actas do curso de actualización sobre a romanización de Galicia, Lugo, 65-83.

Santos Yanguas, J. - Dopico Caínzos, Ma D. (e.p.): "El impacto de Asturica Augusta sobre los indígenas", Revista de Historiografía.

Santos Yanguas, N. (2006): Asturias, los astures y la cultura castreña, Oviedo. 